This is the final peer-reviewed accepted manuscript of:

Forte, L., Torricelli, P., Boanini, E., Gazzano, M., Fini, M., Bigi, A., Antiresorptive And Anti-Angiogenetic Octacalcium Phosphate Functionalized With Bisphosphonates: An In Vitro Tri-Culture Study, Acta Biomaterialia (2017).

The final published version is available online at:

http://dx.doi.org/10.1016/j.actbio.2017.02.040

Rights / License:

The terms and conditions for the reuse of this version of the manuscript are specified in the publishing policy. For all terms of use and more information see the publisher's website.

This item was downloaded from IRIS Università di Bologna (https://cris.unibo.it/)

When citing, please refer to the published version. 


\section{Antiresorptive And Anti-Angiogenetic Octacalcium Phosphate}

\section{Functionalized With Bisphosphonates: An In Vitro Tri-Culture Study.}

Lucia Forte $^{\mathrm{a}}$, Paola Torricelli ${ }^{\mathrm{b}}$, Elisa Boanini ${ }^{\mathrm{a}, *}$, Massimo Gazzano $^{\mathrm{c}}$, Milena Fini ${ }^{\mathrm{b}}$, Adriana Bigi ${ }^{\mathrm{a}}$

a'Department of Chemistry “G. Ciamician”, University of Bologna, via Selmi 2, 40126 Bologna, Italy

${ }^{\mathrm{b}}$ Laboratory of Preclinical and Surgical Studies, Research Institute Codivilla Putti Rizzoli Orthopaedic Institute, via di Barbiano 1/10, 40136 Bologna, Italy 'ISOF-CNR , c/o Department of Chemistry “G. Ciamician”, Bologna, Italy

*Corresponding author. Tel: +39 051 2099548; fax: +39 051 2099456;

e-mail: elisa.boanini@unibo.it 


\section{Abstract}

Development of new materials for the local administration of bisphosphonates (BPs) is aimed to avoid the negative side effects of prolonged systemic use of these potent drugs. In this work, we synthesized octacalcium phosphate (OCP) in the presence of two potent BPs and obtained a single crystalline phase up to a zoledronate and alendronate content of $3.5 \mathrm{wt} \%$ and $5.2 \mathrm{wt} \%$, respectively. Both BPs provoke minor structural modifications and a reduction of the crystal dimensions of OCP, which suggests a preferential interaction of the BPs with the structure of the calcium phosphate. Alendronate containing samples display increased values of zeta potential with respect to that of $\mathrm{OCP}$, and an initial burst release of the BP in solution. At variance, the zeta potential of zoledronate functionalized samples decreases on increasing the content of zoledronate, which is not appreciably released in solution. Bone microenvironment response to the composite materials was investigated in vitro using a triculture model. BP functionalized samples downregulate the viability of the cells, sustain osteoblast differentiation and accelerate the production of collagen type I and osteocalcin. At variance, they inhibit monocyte differentiation into osteoclast and provoke a dose dependent reduction of VEGF production, exhibiting antiresorptive and antiangiogenetic properties that can be usefully exploited for the local treatment of abnormal bone losses.

Keywords: octacalcium phosphate, alendronate, zoledronate, triculture, osteoporosis 


\section{Introduction}

Bisphosphonates (BPs) are routinely employed for the treatment of high-turnover bone diseases related to an imbalance between osteoblast bone formation and excessive osteoclast bone resorption, such as osteoporosis, Paget's disease, hypercalcemia and metastatic cancer [1]. Furthermore, the results of a number of pre-clinical studies indicate that BPs display also antitumor activities [2,3]. In particular, aminobisphosphonates (N-BPs) such as alendronate (AL) and zoledronate (ZOL) inhibit farnesyl pyrophosphate synthase activity in the mevalonate pathway, hindering the prelynation of small GTPases signaling proteins. This mechanism blocks many osteoclast activities and it is suggested to be responsible for the direct antitumor effect of N-BPs [2,3]. Moreover, indirect anticancer activities of N-BPs include interaction with macrophages and endothelial cells [4]. In fact, both ZOL and AL have been reported to inhibit endothelial cell adhesion, migration and proliferation, and to interfere with tumor angiogenesis [5-8]. However, N-BPs potentiality as effective anticancer drugs is remarkably affected by their unfavorable pharmacokinetics, since most of systemic administrated N-BPs rapidly binds to the skeleton or is cleared via renal filtration [9]. Poor bioavailability is just one of the drawbacks of the systemic administration of these drugs, which have several side effects, including osteonecrosis of the jaw and atypical subtrochanteric fractures [10,11]. Local administration at specific bone sites has been proposed as an alternative strategy to deliver N-BPs and avoid the potentially negative effects of their prolonged systemic use [12]. Calcium phosphates powders, cements and coatings are among the main delivery systems which have been proposed to this aim, whereas hydroxyapatite and $\beta$-tricalcium phosphate are the most used CaPs in this field [13-19]. In particular, we previously showed that hydroxyapatite (HA) can be functionalized with alendronate, as well as with zoledronate, through synthesis in aqueous solution $[19,20]$. BPs incorporation into HA 
nanocrystals, which reached a maximum amount of about $7 \mathrm{wt} \%$ both in HA-AL and in HA-ZOL, yielded materials able to exert a beneficial influence on in vitro osteoblast proliferation and differentiation, and to inhibit osteoclast proliferation and activity. In the present work, we explored the possibility to functionalize octacalcium phosphate (OCP) with alendronate and zoledronate, with the aim to get new biomaterials for the local treatment of diseases characterized by abnormal bone loss. OCP has been proposed as a valid alternative to HA for the preparation of biomaterials for hard tissue repair, due to its high speed of resorption and osteoconductivity, which has been related to its rapid conversion into apatite in a biological environment [21-24]. In fact, OCP is considered the precursor phase of biological apatites, and its triclinic crystal structure exhibits remarkable similarities with the hexagonal HA $[25,26]$. The possibility to functionalize OCP with BPs through synthesis in aqueous solution, in order to get materials able to couple the good biological performance of OCP with the therapeutic properties of the bisphosphonates, has not been explored up to now. Herein we carried out a chemical, structural and morphological characterization of the products obtained by synthesizing $\mathrm{OCP}$ in the presence of increasing concentrations of $\mathrm{AL}$ and ZOL. Bone cells response to the synthesized materials was tested in vitro using a triculture model involving osteoblasts, osteoclast and endothelial cells in order to mimic bone microenvironment. The functionalized materials sustain osteoblast activity, whereas they inhibit endothelial cells and osteoclast differentiation, displaying anti-resorptive and anti-angiogenetic properties, which could be usefully exploited for the local treatment of abnormal bone losses. 


\section{Materials and Methods.}

\subsection{Synthesis and characterization}

\subsubsection{Synthesis}

The synthesis of OCP was carried out by dropwise addition of $250 \mathrm{ml}$ of $0.04 \mathrm{M}$ $\mathrm{Ca}\left(\mathrm{CH}_{3} \mathrm{COO}\right)_{2}$ (over a period of $50 \mathrm{~min}$ ) into $750 \mathrm{ml}$ of a phosphate solution containing $5 \mathrm{mmol}$ of $\mathrm{Na}_{2} \mathrm{HPO}_{4}$ and $5 \mathrm{mmol}$ of $\mathrm{NaH}_{2} \mathrm{PO}_{4}$ at starting $\mathrm{pH}$. The reaction was carried out at $70^{\circ} \mathrm{C}$ under mechanical stirring. After $30 \mathrm{~min}$ the precipitate was filtered, repeatedly washed with distilled water and dried at $37^{\circ} \mathrm{C}$.

Similarly the synthesis of OCP in the presence of Alendronate was carried out by dropwise addition of $250 \mathrm{ml} \mathrm{Ca}\left(\mathrm{CH}_{3} \mathrm{COO}\right)_{2}$ solution into $700 \mathrm{ml}$ of a phosphate solution containing $5 \mathrm{mmol}$ of $\mathrm{Na}_{2} \mathrm{HPO}_{4}$ and $5 \mathrm{mmol}$ of $\mathrm{NaH}_{2} \mathrm{PO}_{4}$ at starting $\mathrm{pH} 5$; afterwards the resulting slurry was stored under stirring for $30 \mathrm{~min}$ and then $50 \mathrm{ml}$ of the sodium alendronate trihydrate (Chemos $\mathrm{GmbH})$ solution was added dropwise over a period of 10 min. Immediately after the addition of Alendronate, the precipitate was filtered, repeatedly washed with distilled water and dried at $37^{\circ} \mathrm{C}$. Alendronate concentration was in the range $0.1-1.5 \mathrm{mM}$, calculated on the final volume. As a consequence samples were labeled as OALXX where $\mathrm{XX}$ indicates the concentration of BP in solution (expressed as $\mathrm{mM}$ ).

The synthesis of OCP in the presence of Zoledronate was performed in the same condition of the modified synthesis of OCP-Alendronate. Disodium zoledronate tetrahydrate $(\mathrm{Chemos} \mathrm{GmbH})$ concentration was in the range $0.1-1.5 \mathrm{mM}$, calculated on the final volume. Samples were labeled as OZOLXX similarly to OALXX ones.

\subsubsection{X-ray diffraction analysis}

X-Ray diffraction analysis was carried out by means of a PANalyticalX'Pert PRO powder diffractometer equipped with a fast $\mathrm{X}^{\prime}$ Celerator detector. Ni-filtered $\mathrm{CuKa}$ radiation was used $(40 \mathrm{~mA}, 40 \mathrm{kV})$. For phase identification the $2 \theta$ range was 
investigated from 3 to $602 \theta$ degrees with a step size of $0.1^{\circ}$ and time/step of $100 \mathrm{~s}$. To evaluate the coherence lengths of crystalline domains and to perform the full profile pattern refinement, further X-ray powder data were collected with a fixed counting time of $400 \mathrm{~s}$ for each $0.033 / \mathrm{step}$. Silicon was used as internal standard. The coherence lengths of crystalline domains were calculated according to the Scherrer formula [19]. For cell parameters evaluation, data were processed with the Rietveld routine of the HighScore Plus software package (PANalytical).

XRD analysis at increasing temperature was performed by using an Anton Paar TTK450 sample stage. The temperature was increased at $20^{\circ} \mathrm{C} / \mathrm{min}$ and the data collection was performed at the temperatures reported on the figures by scanning from 3.5 to $40^{\circ}$ $2 \theta$ degrees counting 40 s each $0.05^{\circ}$ step (with the fast $X^{\prime}$ Celerator detector an XRD scan was collected in 40 s).

\subsubsection{Morphological analysis}

Morphological investigations of crystals were performed using a Phenom ProX desktop-scanning electron microscope at beam acceleration voltage of $10 \mathrm{kV}$. The samples were obseryed as prepared and not sputter coated before examination. The ImageJ $®$ picture analyzer software was used to estimate the mean crystals dimensions, averaging the measurements over at least 200 data points per sample. t-test was employed to assess statistical significance of the results. $\mathrm{P}<0.05$ was considered statistically significant.

\subsubsection{Evaluation of bisphosphonate content}

Bisphosphonate content was determined spectrophotometrically via complex formation with Fe(III) ions using a Varian Cary50Bio instrument ( $\lambda=290 \mathrm{~nm})$ [27].

\subsubsection{Zeta potential}

Zeta potential was measured using a Malvern Instruments Zetasizer Nano. $5 \mathrm{mg}$ of powder sample was suspended in $50 \mathrm{~mL}$ of MilliQ water after sonication for 2 minutes. 
Spontaneous $\mathrm{pH}$ of all suspensions was about 8.5. Each analysis was performed in triplicate.

\subsubsection{Hydrolysis}

Hydrolysis tests were carried out on $100 \mathrm{mg}$ of powders in $50 \mathrm{ml}$ of $0.04 \mathrm{M}$ HEPES solution at $\mathrm{pH}$ of 7.4 , adjusted with $\mathrm{NaOH}$. The solutions were stored at $60^{\circ} \mathrm{C}$ for a period of time from 2 days up to 30 days.

\subsubsection{Bisphosphonate release}

Release tests were performed on disk-shaped samples $(\varnothing=6.0 \mathrm{~mm})$. Each disk was prepared by pressing $60 \mathrm{mg}$ of powder into cylindrical moulds by using a standard evacuable pellet die (Hellma).

The samples were immersed in $2 \mathrm{ml}$ of $0.1 \mathrm{M}$ Phosphate Buffer Solution (PBS) at $\mathrm{pH}$ of 7.4 for increasing time from 2 hours up to 7 days. The content of bisphosphonate was measured spectrophotometrically on the solid residue via complex formation with Fe(III) ions using a Varian Cary50Bio instrument ( $\lambda=290 \mathrm{~nm})$.

\subsubsection{AFM analysis}

Cells response is greatly influenced by the roughness of the materials. Thus, we investigated the surface of the disk shaped samples through AFM analysis. AFM imaging of the disk-shaped samples was performed a Veeco Nanoscope 3D instrument. The samples were analyzed in tapping mode using a $\mathbf{J}$ scanner (maximum scan size 150 $\mu \mathrm{m}$ ) and phosphorus (n) doped silicon probes (spring constant 20-80 N/m; resonance frequency $250-290 \mathrm{kHz}$; nominal tip radius <10 nm). Roughness parameters, namely arithmetic mean roughness $(\mathrm{Ra})$, root-square roughness $(\mathrm{Rq})$, and the vertical distance between the highest and lowest points within the evaluation length (Rt), were recorded.

\subsection{In vitro triculture model}

For in vitro tests the disk-shaped samples were sterilized using gamma rays (Cobalt-60) at a dose of $25 \mathrm{kGy}$. 
Human osteoblast-like cells MG63 (OB, Istituto Zooprofilattico Sperimentale IZSBS, Brescia, Italy), human monocytes (OC), and human umbilical vein endothelial cells (HUVEC, IZSBS) were used for the triculture model. OB were expanded in DMEM supplemented with $10 \%$ FCS, $1 \%$ antibiotics (100 U/ml penicillin, $100 \mu \mathrm{g} / \mathrm{ml}$ streptomycin), $\beta$-Glycerophosphate $\quad\left(10^{-4} \mathrm{M}\right)$ and Ascorbic acid $(50 \mu \mathrm{g} / \mathrm{ml})$.

Mononuclear cells were isolated from peripheral human blood of healthy adult volunteers (Rizzoli Orthopedic Institute Ethic Comittee approval n.33154, 12/09) by density gradient centrifugation and cultured in osteoclast differentiating medium (DMEM additioned with macrophage colony-stimulating factor, MCSF, 25ng/ml and receptor activator for êB factor ligand, RANKL, 30ng/ml).

HUVEC were seeded in $1 \%$ gelatin coated plate, in complete medium EBM-2 (Clonetics LONZA, Walkersville, MD, USA).

Samples of OCP (as reference), and of OCP synthesized in presence of Alendronate (OAL0.6, OAL1.2), or Zoledronate (OZOL0.6) were placed in 24 wells plates. OB and OC were cultured in direct contact with biomaterials a concentration of $2 \times 10^{4}$ cells $/ \mathrm{cm}^{2}$ and $4 \times 10^{5}$ cells $/ \mathrm{cm}^{2}$ respectively. OB were seeded onto the surface of the samples, and OC were seeded in the bottom of the well, around the samples. HUVEC $\left(1 \times 10^{4} \mathrm{cells} / \mathrm{cm}^{2}\right)$ were added in transwells insert $0.4-\mu \mathrm{m}$ pore size (Millipore, Ireland) to all wells with samples.

The medium was a mixture of each specific culture medium according to cell density proportion and was replaced twice a week. Tri-cultures were maintained in standard conditions, at $37^{\circ} \mathrm{C} \pm 0.5$ with $95 \%$ humidity and $5 \% \mathrm{CO}_{2} \pm 0.2$, up to 14 days.

\subsubsection{Cell viability}

To test cell viability of each culture at 1 and 2 weeks ( $1 \mathrm{w}$ and $2 \mathrm{w}$ respectively), Alamar blue dye (Serotec, Oxford, UK) was added to OB, OC and HUVEC of disassembled triculture $(1: 10 \mathrm{v} / \mathrm{v})$, and the multi-well plates were incubated for $4 \mathrm{~h}$ at $37^{\circ} \mathrm{C}$. The reagent 
is a dye which incorporates an oxidation-reduction (REDOX) indicator that changes color in response to the chemical reduction of growth medium, resulting from cell growth. The absorbance was read spectrophotometrically at 570 and $600 \mathrm{~nm}$ wavelengths (for the fully oxidized and reduced forms of reagent) by MicroPlate reader (BioRad, CA, USA). The optical density (OD) values were processed following manufacturer's instruction and expressed as reduction percentage. Results are given as percentage of OCP at $1 \mathrm{w}$ (considered as 100\%).

\subsubsection{Cell differentiation and activity}

At the end of experimental times cell supernatants of all samples were collected and centrifuged to remove particulates, if any. They were maintained at $-20^{\circ} \mathrm{C}$ to be used for detecting the following immunoenzymatic assay: Osteoprotegerin (OPG, Boster Biological Technology, Ca, USA), Receptor Activator for Nuclear factor KB Ligand (RANKL, Boster), Collagen type I (COLL1, Cloud-Clone USCN Life Science, Wuhan, China), Osteocalcin (OSTC, e-Biosciences Bender MedSystem, Vienna, A), Vascular Endothelial Growth Factor (VEGF, e-Biosciences).

TRAP-staining was performed at 14 days to assess osteoclast differentiation according to manufacturer's instructions (SIGMA, Buchs, Switzerland). The positive cells developed red colour of different intensity. The number of TRAP-positive multinucleated cells (three or more nuclei each cell) was counted under the microscope by a semiautomatic software (NIS-Elements AR 4.30.01) and results are given as percentage of OC control culture considered as $100 \%$.

\subsubsection{Cell morphology}

Samples for each material, at the end of the experiment, were processed for Scanning Electron Microscopy (SEM): osteoblasts grown on the materials and endothelial cells in the transwell were fixed in $2.5 \%$ glutaraldehyde, in $\mathrm{pH} 7.4$ phosphate buffer $0.01 \mathrm{M}$ for $1 \mathrm{~h}$ and dehydrated in a graded ethanol series. After a passage in hexamethyldisilazane, 
the samples were air dried. The samples were sputter-coated with $\mathrm{Pd}$ prior to examination with a HITACHI S-2400 Scanning Electron Microscope.

\subsubsection{Statistical Analysis}

Statistical evaluation of data was performed using the software package SPSS/PC Statistics ${ }^{\mathrm{TM}} 23$ (SPSS Inc., Chicago, IL USA). The results presented are the mean of six biological replicates each group. Data are reported as mean \pm standard deviations (SD) at a significance level of $\mathrm{p}<0.05$. After having verified normal distribution and homogeneity of variance, a one-way ANOVA was done for comparison between groups. Finally, a post hoc multiple comparison test was performed to detect significant differences among experimental groups and controls. Pearson test was performed to detect correlation between data.

\section{Results and Discussion}

\subsection{Chemical and structural characterization}

The results of the X-ray diffraction analysis indicate that alendronate functionalized octacalcium phosphate can be obtained up to a bisphosphonate concentration in solution of $1.2 \mathrm{mM}$. The XRD patterns of the products, reported in Fig. 1 are indeed consistent with the presence of octacalcium phosphate as unique crystalline phase up to sample OAL1.2, whereas the pattern of OAL1.5 exhibits the presence of two additional peaks at about $9.1^{\circ}$ and $12.8^{\circ}$ of $2 \theta$, indicating the presence of a small amount of crystalline calcium alendronate [28]. The presence of AL in the composite nanocrystals does not provoke significant variations in the values of the lattice constants, which are close to those calculated for pure OCP (Table S1). At variance, the broadening of the diffraction reflections displays a modest increase on increasing alendronate content, suggesting a reduction of the coherent length of the scattering domains. 
A quantitative estimation of the size of the coherently scattering domains (i.e. the crystallite size) was performed from the line broadening of the (100), (002) and (010) reflections. The lengths of the coherent domains $\left(\tau_{\mathrm{hkl}}\right)$ were calculated from the widths at half maximum intensity $\left(\beta_{1 / 2}\right)$ using the Scherrer equation [19]:

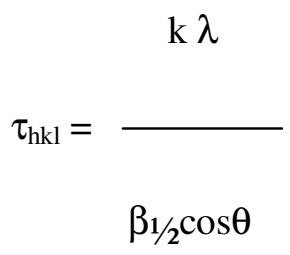

where $\lambda$ is the wavelength, $\theta$ the diffraction angle and $K$ a constant depending on crystal habit (chosen as 0.9). $\tau_{\mathrm{hkl}}$ values show a general trend to decrease on increasing alendronate concentration (Table 1).

The amount of alendronate contained in the solid products, which was determined through spectrophotometric analysis of the chromophoric complex with FeIII ions [27], increases as a function of alendronate concentration in solution up to a maximum value of about $5.2 \mathrm{wt} \%$ (Table 1).

Alendronate presence provokes also a reduction of the mean dimensions of the crystals, as it can be inferred from the SEM images reported in Fig. 2. The relative size histograms reported in Fig. 2 show that the decrease of the mean size is greater along the width of the crystals than along their length (Table S2). Accordingly, the length/width ratio passes from about 10 to about 15 on going from pure OCP to

OAL1.2, suggesting a preferential interaction of alendronate with the $(0 \mathrm{k} 0)$ faces of OCP structure.

The zeta potential of OCP was found to be $-7.78 \mathrm{mV}$, in agreement with the basic $\mathrm{pH}$ of the solution (about 8.5) [29]. The samples prepared in the presence of alendronate exhibit a modest increase of the zeta potential values, with no significant variation as a function of alendronate, as shown in Table 1. These findings could be related to the data 
on alendronate release. Fig. 3 shows that all OALXX samples display an initial burst release, after which they reach a constant BP content. After release, the different solid samples exhibit similar values of alendronate content (about 2.0-2.5 wt \%), which could justify the similar values of zeta potential. On this basis, it can be suggested that a great part of alendronate is loosely bound to OCP crystals and easily lost in solution, whereas the part retained in the solid products involves a stronger interaction with the calcium phosphate. As a consequence, the amounts released from the different samples (more loosely bound) are greater in the samples at higher loading contents, whereas the differences among the samples OAL0.1 - OAL0.3 - OAL0.6 are small and within the experimental error.

The range of zoledronate concentration in solution that allows to obtain OCP as a single crystalline phase is reduced with respect to that verified for alendronate. In fact, the XRD patterns reported in Fig. 1 shows that OZOL0.9 contains also a second phase, in agreement with the presence of the peaks at 9.6, 13.2 and $18.6{ }^{\circ}$ of $2 \theta$ and corresponding to the most intense peaks of crystalline calcium zoledronate [30]. The presence of the second phase is supported by SEM images where much smaller thin elongated crystals are visible together with the big plate-like crystals characteristic of OCP (Fig. 4). Zoledronate content in the solid products increases with its concentration in solution up to about $3.5 \mathrm{wt} \%$ (Table 1). As observed for alendronate, the incorporation of zoledronate does not induce significant modifications of the lattice parameters of OCP (Table S1), whereas it significantly reduces the mean lengths of the coherently scattering domains (Table 1) (in all the crystallographic directions).

OCP crystals synthesized in the presence of zoledronate tend to aggregate: SEM images of all ZOLXX samples show the presence of both separate crystals and spherulites, with the relative amount of aggregates increasing with increasing ZOL content (Fig. 4). Moreover, the crystal dimensions decrease on increasing ZOL content, provoking a 
similar increase of the length/width ratio as that observed for OALXX samples, as it can be appreciated in the histograms shown in Fig. 4.

At variance with the results obtained for OALXX samples, OZOLXX composite samples do not show appreciable BP release in solution, as it appears from the graph in Fig. 3, indicating a stronger interaction of ZOL with OCP structure. The stronger binding affinity of ZOL than AL towards hydroxyapatite was previously justified by the possibility of ZOL to form two $\mathrm{H}$ bonds with HA structure and by the availability of a favorable $\mathrm{Ca}$ ions coordination geometry $[3,19]$. The same argument can be extended to discuss the different interaction of $\mathrm{ZOL}$ and $\mathrm{AL}$ with $\mathrm{OCP}$, in view of the similarity between OCP and hydroxyapatite structure. A sketch of possible interactions between OCP structure and BPs is reported in Fig. 5.

The values of zeta potential of ZOLXX samples reduce significantly on increasing BP content, down to $-20 \mathrm{mV}$ (Table 1). A similar effect of zoledronate on zeta potential was previously reported for hydroxyapatite crystals at different ZOL content; the shift of the zeta potential towards negative values was interpreted as due to the binding of negatively charged phosphonate groups to $\mathrm{Ca}^{2+}$ sites on the surface of hydroxyapatite, which becomes more negative [31]. Previous results on the different influence of zoledronate and alendronate on the zeta potential of hydroxyapatite as a function of BPs concentration in solutions [32] were justified on the basis of the different pKa of AL and ZOL functional groups.

OCP in water hydrolyzes to HA. The results of hydrolysis tests carried out on pure OCP show that after three days storage in solution at $\mathrm{pH} 7.4$ and at $60^{\circ} \mathrm{C}$, it completely converts into HA (Fig. S1). On the contrary, the composite OALXX and OZOLXX crystals do not exhibit any conversion into HA even after 30 days (Fig. S2), indicating that the presence of BPs prevents the hydrolysis reaction. It can be suggested that the interaction with BPs stabilizes OCP structure and inhibits its conversion into HA. On 
the other hand, BPs do not influence the thermal stability of OCP. The XRD patterns recorded from pure OCP at increasing temperatures show the onset of a shoulder next to the (100) small angle reflection at $4.7^{\circ} 2 \theta$, together with a variation towards an apatitic pattern in the higher angles region. Above $200^{\circ} \mathrm{C}$, the split of the low angle reflection in two peaks and the onset of a new peak at $5.2^{\circ} 2 \theta$ suggest the presence of a further phase, previously identified as "collapsed OCP" [33], whereas above $250^{\circ} \mathrm{C}$ the pattern displays the characteristics of a poor crystalline apatitic phase. The same trend has been observed for OALXX and OZOLXX samples, as shown in Fig. S3 for the sample OZOL0.6.

\subsection{In vitro tests}

In vitro tests were performed using a triculture model of bone cells, namely osteoblast, osteoclast and endothelial cells, on OCP, as control material, OAL1.2 and OZOL0.6, which are the samples at the highest content of the two bisphosphonates, as well as on OAL0.6, which contains about the same amount of BP as OZOL0.6 (about 3.5 wt\%). In vitro tests were performed on disk-shaped samples in order to avoid the influence of the different particle morphology on cell response [34]. The surfaces of the disk-shaped samples do not exhibit any significant difference as a function of composition, as it can be appreciated in the SEM images reported in Fig. S4. In agreement, the results of AFM investigation provide similar roughness parameters, $\mathrm{Ra}, \mathrm{Rq}$ and $\mathrm{Rt}$, for the different samples. Average values were: $\mathrm{Ra}=0.178 \pm 0.014 \mu \mathrm{m}, \mathrm{Rq}=0.220 \pm 0.022 \mu \mathrm{m}$, $\mathrm{Rt}=1.681 \pm 0.065 \mu \mathrm{m}$, close to those previously reported for disk shaped OCP samples [35].

Data of BPs release (Fig.3) indicate that the amount of released ZOL is very low, whereas AL exhibits an initial burst release and reaches a steady state in a few hours. This means that at longer times, and in particular at 1 and 2 weeks when in vitro tests are performed, BPs are not significantly released. Nonetheless, the results of in vitro 
tests reported below show that viability and the tested differentiation markers are influenced by the presence of BPs in the composite materials. It could be speculated that $\mathrm{OB}$ and $\mathrm{OC}$, which are in contact with the materials, are influenced by the presence of BPs on the surface of the materials, whereas the products of their metabolism influence HUVEC in the transwell.

\subsubsection{Osteoblast viability and differentiation}

The presence of AL and ZOL in the composite materials deeply affects the growth of the cells when compared to OCP reference material as shown in Fig. 6. The decrease of osteoblast viability of BPs containing groups in comparison with OCP depends on the concentration and type of bisphosphonates. In fact OZOL0.6 group shows a significant lower value of $\mathrm{OB}$ viability when compared to all groups at $1 \mathrm{w}$, whereas OAL1.2, OAL0.6 exhibit higher values, although significantly lower than OCP. At 2w, osteoblast viability on BPs containing samples significantly increases in comparison to $1 \mathrm{w}$ values $(\mathrm{p}<0.0005)$, but it is still significantly lower on OAL1.2 and OZOL0.6 than on OCP and OAL0.6. Moreover, OZOL0.6 viability is significantly lower also with respect to OAL1.2. However, at the end of the experimental time the surfaces of all the samples appear well covered with osteoblasts, which are well attached and rich of filopodia, as it can be appreciated in the SEM images reported in Fig. S5. The effects of bisphosphonates on the triculture model are showed by the measure of some molecules representative of osteoblast metabolism and of their interplay with osteoclast and endothelial cells.

The process of bone remodeling was investigated through the pathway that involves OPG and RANKL (Fig. 8). Osteoblast and osteoclast interplay in the balance between bone regeneration and resorption is influenced by bisphosphonates action. Both OAL0.6 and OZOL0.6 significantly stimulate osteoblast production of OPG. RANKL levels seem not to be particularly affected in the cultures, but the OPG/RANKL ratio shows a 
significantly higher value in OAL0.6 group when compared to OAL1.2 (both at $1 \mathrm{w}$ and 2w), OCP (2w), and OZOL0.6 (1w). It has been suggested that high OPG levels promote bone formation over bone resorption, whereas OPG/RANKL ratio has been shown to downregulate osteoclast differentiation [36,17]. The concentration of alendronate in OAL1.2 is most likely too high to stimulate OPG production. On the other hand, the enhancement of the values of OPG and OPG/RANKL ratio in OAL0.6 (1w and 2w) and OZOL0.6 (2w) groups suggests a beneficial effect of these materials on promotion of bone formation and inhibition of bone resorption,

Collagen type 1 (Fig. 8) was produced at higher levels in all bisphosphonate containing groups when compared to OCP at $1 \mathrm{w}$, whereas the trend was reversed at $2 \mathrm{w}$, suggesting that the presence of bisphosphonates accelerates cell production of COLL1.

Also the deposition of osteocalcin (Fig. 8) displays a different trend from 1 to 2 weeks of culture. At 1w its level is significantly higher in OZOL0.6 in comparison to OCP and OAL0.6, whereas at $2 \mathrm{w}$ osteocalcin level increases on OCP and OAL0.6, with OAL0.6 displaying higher values than OAL1.2.

The analysis of OPG/RANKL ratio, COLL1 and OSTC, as markers of osteoblast differentiation, measured in cell supernatant, demonstrate that osteoblast grown in presence of the composite materials are differently influenced by composition. The observed decrease of cell proliferation on the samples containing bisphosphonates is in agreement with the accelerated osteoblast differentiation in term of COLL1 and OSTC production, which is particularly enhanced on OZOL0.6 and OAL1.2.

\subsubsection{Osteoclast viability and differentiation}

The results of Alamar Blue test indicate that the viability of monocytes is significantly reduced in the presence of bisphosphonates containing materials. At both experimental times, mononuclear cells seeded on OAL1.2 and OAL0.6 are significantly lower than OCP, but significantly higher than OZOL0.6. Both AL and ZOL exert a toxic effect on 
osteoclast, which viability shows a dramatic decrease, more significant for OZOL0.6 in comparison with AL containing samples, at both concentrations.

Generation of osteoclast from peripheral blood mononuclear cells precursor after 14 days of culture was assessed by large multinucleated cells positive to TRAP staining. Representative pictures are showed in Fig. 7. Osteoclastogenesis process on OCP reference material (98\%) is similar to control (100\%), showing a regular development of multinucleated purple cells. On the contrary, osteoclasts differentiation, as well as their viability, is strongly lowered in presence of both AL containing samples (OAL1.2: 7\%; OAL0.6: 8\%) and OZOL0.6 (5\%), independently by the concentration.

Moreover, osteoclast differentiation is influenced by OPG expression by osteoblast, which modifies OPG/RANKL ratio. OPG is a decoy receptor for RANKL. By blocking the RANKL-RANK link, it counteracts bone-resorbing activity, as it is associated to a decrease of osteoclast number. The increase of the values of OPG and OPG/RANKL ratio in OAL0.6 and OZOL0.6 groups can influence the cocultured osteoclasts, inhibiting their activity $[19,37]$.

It can be concluded that BPs containing groups display a toxic action on osteoclast both directly on viability and differentiation (all groups) and indirectly on differentiation by the OPG/RANKL pathway (OAL0.6 and OZOL0.6).

\subsubsection{HUVEC viability and differentiation}

HUVEC grown in the presence of OCP appear numerous, well spread onto the transwell and very rich of filopodia, whereas they appear more rounded and less numerous on bisphosphonate containing samples, especially when grown in the presence of OZOL0.6 (Fig. S5). Differences were also found in HUVEC viability. All groups with bisphosphonates show a decrease in viability when compared to OCP reference group at $1 \mathrm{w}$, whereas at $2 \mathrm{w}$ only the values measured for OAL1.2 and OZOL0.6 are significant lower than OCP. These results are in agreement with the increasing number of 
preclinical studies, which indicates that NBPs in vitro interfere with the functional activity of endothelial cells and display anti-angiogenetic properties, which contributes to their antitumor activity $[4,6,38,39]$.

The dosage of VEGF (Fig. 8), which is released by both osteoblast and HUVEC, shows a partial downregulation by bisphosphonates in the triculture model in OAL0.6 and OZOL0.6, although values are not significantly different from OCP. On the contrary, a significant decrease is reached in OAL1.2 group when compared to OCP $(2 \mathrm{w})$. Osteoblast and osteoclast precursor recruitment is favored through capillary genesis, but bisphosphonates, especially at high concentration, may alter this process. The decrease of VEGF confirms the anti-angiogenetic properties of the BPs containing materials, since VEGF acts as a mediator stimulating angiogenesis in the microenvironment of bone remodeling. In fact serum VEGF has been proposed as marker of BPs related osteonecrosis of the jaw. Our results, which show that VEGF production is affected in the presence of relatively high content of $\mathrm{BP}$, are in agreement with literature data that indicate that high BPs concentrations could exert an anti-angiogenic activity whereas low concentrations appear to do not significantly affect angiogenic processes, [40,41].

\section{Conclusions}

Functionalization of octacalcium phosphate with BPs allowed to obtain composite materials containing up to 3.5 and $5.2 \mathrm{wt} \%$ of zoledronate and alendronate, respectively.

The incorporation of both bisphosphonates provokes a slight decrease of the mean length of the coherent scattering domains, as well as morphological modifications that suggests a preferential interaction with the (0k0) faces of OCP. Both ZOL and AL stabilize OCP, preventing its hydrolysis into HA. However, release data suggest a stronger interaction of ZOL than AL with OCP structure. The presence of ZOL in the composite crystals has also a greater effect on bone cells viability. All BPs containing 
samples, despite a decrease of proliferation rate, promote $\mathrm{OB}$ production of collagen type I and osteocalcin. Moreover, OAL0.6 and OZOL0.6 enhance OPG production, without significantly influence RANKL values. On the other hand, monocytes viability and their differentiation in OC are significantly inhibited by the presence of BPs in the composite materials. These data, together with the observed reduction of HUVEC viability in all samples and of VEGF production at relatively high BP content, suggest that zoledronate and alendronate maintain their antiresorptive and anti-tumor properties even when incorporated into OCP.

\section{Disclosure of potential conflicts of interest}

The authors declare no conflict of interest.

\section{Acknowledgements}

The authors are grateful to the University of Bologna (FARB 2012) and to Rizzoli Orthopaedic Institute (5 X 1000 year 2013 Project "Sviluppo e validazione di modelli alternativi e complementari in vitro (intelligent testing strategy) in ortopedia e traumatologia"). 


\section{References}

[1] R.G.G. Russell, Bisphosphonates: the first 40 years, Bone 49 (2011) 2-19.

[2] V. Stresing, F. Daubiné, I. Benzaid, H. Mönkkönen, P. Clézardin, Bisphosphonates in cancer therapy, Cancer Lett. 257 (2007) 16-35.

[3] R.G.G. Russell, N. B. Watts, F. H. Ebetino, M. J. Rogers, Mechanisms of action of bisphosphonates: similarities and differences and their potential influence onclinical efficacy. Osteoporos. Int. 19 (2008) 733-759.

[4] V. Stresing, P. G. Fournier, A. Bellahcène, I. Benzaïd, H. Mönkkönen, M. Colombel, F. H. Ebetino, V. Castronovo, P. Clézardin, Nitrogen-containing bisphosphonates can inhibit angiogenesis in vivo without the involvement of farnesyl pyrophosphate synthase, Bone 48 (2011) 259-266.

[5] D. Santini, B. Vincenzi, S. Galluzzo, F. Battistoni, L. Rocci, O. Venditti, G. Schiavon, S. Angeletti, F. Uzzalli, M. Caraglia, G. Dicuonzo, G. Tonini, Repeated intermittent low-dose therapy with zoledronic acid induces an early, sustained, and long-lasting decrease of peripheral vascular endothelial growth factor levels in cancer patients, Clin. Cancer Res. 13 (2007) 4482-4486.

[6] K. Hashimoto, K. Morishige, K. Sawada, M. Tahara, S. Shimizu, S. Ogata, M. Sakata, K. Tasaka, T. Kimura, Alendronate suppresses tumor angiogenesis by inhibiting Rho activation of endothelial cells, Biochem. Biophys. Res. Commun. 354 (2007) 478484.

[7] M. Hasmim, G. Bieler, C. Rüegg, Z, Zoledronate inhibits endothelial cell adhesion, migration and survival through the suppression of multiple, prenylation dependent signaling pathways, J. Thromb. Haemost. 5 (2007) 166-173.

[8] M. Bezzi, M. Hasmim, G. Bieler, O. Dormond, C. Rüegg, Zoledronate sensitizes endothelial cells to tumor necrosis factor-induced programmed cell death: evidence for 
the suppression of sustained activation of focal adhesion kinase and protein kinase B/Akt., J. Biol. Chem. 278 (2003) 43603-43614.

[9] M. McClung, Bisphosphonates, Arq. Bras. Endocrinol. Metabol. 50 (2006) 735-744.

[10] G. Favia, G. P. Pilolli, E. Maiorano, Histologic and histomorphometric featuresof bisphosphonate-related osteonecrosis of the jaws: an analysis of 31 cases with confocal laser scanning microscopy, Bone 45 (2009) 406-413.

[11] R. Rizzoli, K. Åkesson, M. Bouxsein, J. A. Kanis, N. Napoli, S. Papapoulos, J. Y. Reginster, C. Cooper, Subtrochanteric fractures after long-term treatment with bisphosphonates: a European society on clinical and economic aspects ofosteoporosis and osteoarthritis, and international osteoporosis foundation working group report, Osteoporos. Int. 22 (2011) 373-390.

[12] E. Verron, J. M. Bouler, Is bisphosphonate therapy compromised by the emergence of adverse bone disorders? Drug Discov. Today 19 (2014) 312-319.

[13] E. Verron, I. Khairoun, J. Guicheux, J. M. Bouler, Calcium phosphate biomaterials as bone drug delivery systems: a review, Drug Discov. Today 15 (2010) 547552.

[14] L. Kyllönen , M. D’Este, M. Alini, D. Eglin, Local drug delivery for enhancing fracture healing in osteoporotic bone. Acta Biomaterialia 11 (2015) 412-434.

[15] E. Verron, M.L. Pissonier, J. Lesoeur, V. Schnitzler, BH. Fellah, H. PascalMoussellard, P. Pilet, O. Gauthier, J. M. Bouler, Vertebroplasty using bisphosphonateloaded calcium phosphate cement in a standardized vertebral body bone defect in an osteoporotic sheep model. Acta Biomaterialia 10 (2014) 4887-4895.

[16] S. Panzavolta, P. Torricelli, B. Bracci, M. Fini, A. Bigi, Functionalization of biomimetic calcium phosphate bone cements with alendronate, J. Inorg. Biochem. 104 (2010) 1099-1106.

[17] E. Boanini, P. Torricelli, L. Forte, S. Pagani, N. Mihailescu, C. Ristoscu, I. N. Mihailescu, A. Bigi, Antiresorption implant coatings based on calcium alendronate and 
octacalcium phosphate deposited by matrix assisted pulsed laser evaporation. Colloid Surface B 136 (2015) 449-456.

[18] F. Errassifi, S. Sarda, A. Barroug, A. Legrouri, H. Sfihi, C. Rey, Infrared, Raman and NMR investigations of risedronate adsorption on nanocrystalline apatites, J. Colloid Interf. Sci.420 (2014) 101-111.

[19] E. Boanini, P. Torricelli, M. Gazzano, M. Fini, A. Bigi, The effect of zoledronatehydroxyapatite nanocomposites on osteoclasts and osteoblast-like cells in vitro, Biomaterials 33 (2012) 722-730.

[20] E. Boanini, M. Gazzano, K. Rubini, A. Bigi, Composite Nanocrystals Provide New Insight on Alendronate Interaction with Hydroxyapatite Structure, Adv. Mater. 19 (2007) 2499-2502.

[21] S. M. Barinov, V. S. Komlev, Osteoinductive ceramic materials for bone tissue restoration: Octacalcium phosphate (review). Inorg. Mater. Appl. Res. 1 (2010) 175181.

[22] O. Suzuki, S. Kamakura, T. Katagiri, M. Nakamura, B. Zhao, Y. Honda, R. Kamijo, Bone formation enhanced by implanted octacalcium phosphate involving conversion into Ca-deficient hydroxyapatite, Biomaterials 27 (2006) 2671-2681.

[23] O. Suzuki, Octacalcium phosphate: Osteoconductivity and crystal chemistry, Acta Biomater. 6 (2010) 3379-3387.

[24] K. Kobayashi, T. Anada, T. Handa, N. Kanda, M. Yoshinari, T. Takahashi, O. Suzuki, Osteoconductive property of a mechanical mixture of octacalcium phosphate and amorphous calcium phosphate, ACS Appl. Mater. Interfaces 6 (2014) 22602-22611. [25] W. E. Brown, J. P. Smith, J. R. Lehr, A. W. Frazier, Octacalcium phosphate and hydroxyapatite: crystallographic and chemical relations between octacalcium phosphate and hydroxyapatite, Nature 196 (1962) 1048-1055. 
[26] M. Mathew, W. E. Brown, L. W. Schroeder, B. J. Dickens, Crystal structure of octacalciumbis(hydrogenphosphate) tetrakis(phosphate) pentahydrate, Ca8(HPO4)4•5H2O, Cryst. Spectrosc. Res. 18 (1988) 235-250.

[27] J. Kuljanin, I. Jankovic, J. Nedeljkovic, D. Prstojevic, V. Marinkovic, Spectrophotometric determination of alendronate in pharmaceutical formulations via complex formation with Fe(III) ions, J. Pharm. Biomed. Anal. 28 (2002) 1215-1220.

[28] E. Boanini, P. Torricelli, M. Gazzano, M. Fini, A. Bigi, . Crystalline calcium alendronate obtained by octacalcium phosphate digestion: A new chance for local treatment of bone loss diseases? Adv. Mater. 25 (2013) 4605-4611.

[29] W. K. Lee, J. S. Ko, H. M. Kim. Effect of Electrostatic Interaction on the Adsorption of Globular Proteins on Octacalcium Phosphate Crystal Film, J. Colloid Interf. Sci. 246 (2002) 70-77.

[30] D. Liu, S. A. Kramer, R. C. Huxford-Phillips, S. Wang, J. Della Rocca, W. Lin, Coercing bisphosphonates to kill cancer cells with nanoscale coordination Polymers, Polymers. Chem. Commun. 48 (2012) 2668-2670.

[31] E. Boanini, M. Gazzano, A. Bigi, Time course of zoledronate interaction with hydroxyapatite nanocrystals, J. Phys. Chem. C 116 (2012) 15812-15818.

[32] G. H. Nancollas, R. Tang, R. J. Phipps, Z. Henneman, S. Gulde, W. Wu, A. Mangood, R. G. G. Russell, F. H. Ebetino, Novel insights into actions of bisphosphonates on bone: Differences in interactions with hydroxyapatite, Bone 38 (2006) 617-627.

[33] E. Boanini, M. Gazzano, K. Rubini, A. Bigi, Collapsed Octacalcium phosphate stabilized by ionic substitutions, Cryst. Growth Des. 10 (2010) 3612-3617.

[34] C. Danoux, D. Pereira, N. Döbelin, C. Stähli, J. Barralet, C. van Blitterswijk, P. Habibovic, The effects of crystal phase and particle morphology of calcium phosphates 
on proliferation and differentiation of human mesenchymal stromal cells, Adv. Healthc. Mater. 5 (2016) 1775-1785.

[35] E. Boanini, P. Torricelli, M. Gazzano, M. Fini, A. Bigi, The effect of alendronate doped calcium phosphates on bone cells activity. Bone 51 (2012) 944-952.

[36] P. J. Kostenuik, Osteoprotegerin and RANKL regulate bone resorption, density, geometry and strength, Curr. Opin. Pharmacol. 6 (2005) 618-625.

[37] E. Boanini, P. Torricelli, M. Gazzano, E. Della Bella, M. Fini, A. Bigi, Combined effect of strontium and zoledronate on hydroxyapatite structure and bone cell responses. Biomaterials 35 (2014) 5619-5626.

[38] T. Ziebart, A. Pabst, M. O. Klein, P. Kämmerer, L. Gauss, D. Brüllmann, B. AlNawas, C. Walter, Bisphosphonates: restrictions for vasculogenesis and angiogenesis: inhibition of cell function of endothelial progenitor cells and mature endothelial cells in vitro, Clin. Oral Investig. 15 (2011) 105-111.

[39] V. Ribeiro, M. Garcia, R. Oliveira, P. S. Gomes, B. Colaço, M. H. Fernandes, Bisphosphonates induce the osteogenic gene expression in co-cultured human endothelial and mesenchymal stem cells, J. Cell. Mol. Med. 18 (2014) 27-37.

[40] B. Vincenzi, A. Napolitano, A. Zoccoli, M. Iuliani, F. Pantano, N. Papapietro, V. Denaro, D. Santini, G. Tonini, Serum VEGF levels as predictive marker of bisphosphonate-related osteonecrosis of the jaw, J. Hematol. Oncol. 5 (2012) 56.

[41] F. Tas, D. Duranyildiz, H. Oguz, H. Camlica, V. Yasasever, E. Topuz, Effect of zoledronic acid on serum angiogenic factors in patients with bone metastases, Med. Oncol. 25 (2008) 346-349. 


\section{Captions to figures.}

Fig. 1 - X-ray diffraction patterns of the products synthesized in the presence of increasing concentrations of alendronate and zoledronate, compared with that of pure OCP. The symbols indicate the presence of crystalline calcium alendronate $(\nabla)$ and calcium zoledronate $(\boldsymbol{\nabla})$.

Fig. 2 - SEM images of the products synthesized in the presence of increasing concentrations of alendronate compared with that of pure OCP. The histograms show the size distribution along the length and the width of the crystals.

Fig. 3 - Alendronate and zoledronate release from the different samples as a function of time.

Fig. 4 - SEM images of the products synthesized in the presence of increasing concentrations of zoledronate. The histograms show the size distribution along the length and the width of the crystals.

Fig. 5 - Scheme of possible structural interaction between alendronate or zoledronate molecules and the crystalline structure of OCP.

Fig. 6 - Cell viability by Alamar Blue dye is showed for osteoclast and osteoblast direct co-colture on biomaterials (a,b), and for HUVEC indirect transwell co-culture (c) after 1 (1w) and 2 weeks $(2 \mathrm{w})$ of culture. The results are given as $\%$ of dye reduction. The Tamhane post hoc multiple comparison test was performed to detect significant differences between groups $(* \mathrm{p}<0.05 ; * * \mathrm{p}<0.005 ; * * * \mathrm{p}<0.0001)$.

OB 1w : ***OCP vs OAL1.2, OAL0.6, OZOL0.6; ***OZOL0.6 vs OAL1.2, OAL0.6; 2w: $* * *$ OZOL0.6 vs OCP, OAL0.6; **OZOL0.6 vs OAL1.2; ***OAL1.2 vs OCP; OAL0.6.

OC 1w, 2w: ***OCP vs OZOL0.6, OAL0.6, OAL1.2; ***OZOL0.6 vs OAL0.6, OAL1.2.

HUVEC 1w: ***OCP vs OAL0.6, OZOL0.6; **OCP vs OAL1.2; 2w: ***OAL1.2 vs OCP; *OAL1.2 vs OAL0.6; ***OZOL0.6 vs OCP, OAL1.2, OAL0.6.

Fig. 7 - Light microscope representative images of TRAP activity in monocytes after 14 days of co-culture with osteoblast and endothelial cells on biomaterials. Differentiated osteoclast appear as large multinucleated cells (20x magnification).

Fig. 8 - Cell activity and differentiation measured in supernatants of osteoblast, osteoclasts, and endothelial cells cultured together on biomaterials after $1(1 \mathrm{w})$ and 2 weeks $(2 \mathrm{w})$ of culture. The Tamhane post hoc multiple comparison test was performed to detect significant differences between groups $(* \mathrm{p}<0.05 ; * * \mathrm{p}<0.005 ; * * * \mathrm{p}<0.0001)$. 
OPG 1w: ***OAL0.6 vs OCP, OAL1.2, OZOL0.6; 2w: *OAL0.6 vs OAL1.2; *OZOL0.6 vs OCP, OAL1.2.

RANKL not significant;

OPG/RANKL ratio $1 \mathrm{w}: *$ OCP, OAL0.6 vs OAL1.2, OZOL0.6; $2 \mathrm{w}:{ }^{*} \mathrm{OAL} 0.6$ vs OCP, OAL1.2.

COLL1 1w: *OAL1.2, OAL0.6, OZOL0.6 vs OCP; 2w: * OCP, OAL1.2, OAL0.6 vs OZOL0.6

OSTC 1w: *OZOL0.6 vs OCP; OAL0.6; 2w: * OAL0.6 vs OAL1.2

VEGF $2 \mathrm{w} * \mathrm{OCP}$ vs OAL1.2

Table 1. Coherent lengths $\left(\tau_{\mathrm{hkl}}\right)$ of the perfect crystalline domains in the direction normal to (100), (002) and to (010) planes calculated using the Scherrer method; zeta potential $(\xi)$; and bisphosphonate content.

\begin{tabular}{|c|c|c|c|c|c|}
\hline Sample & $\begin{array}{c}\tau_{100} \\
{[\AA]}\end{array}$ & $\begin{array}{c}\tau_{002} \\
{[\AA]}\end{array}$ & $\begin{array}{c}\tau_{010} \\
{[\AA]}\end{array}$ & $\begin{array}{c}\xi \\
{[\mathrm{mV}]}\end{array}$ & $\begin{array}{c}\text { BP } \\
\text { content } \\
{[\mathrm{wt} \%]}\end{array}$ \\
\hline OCP & $545(21)$ & $816(48)$ & $604(21)$ & -7.8 & -- \\
\hline OAL0.1 & $530(49)$ & $796(41)$ & $617(10)$ & -3.0 & 3.0 \\
\hline OAL0.3 & $515(40)$ & $759(62)$ & $606(18)$ & -2.0 & 3.2 \\
\hline OAL0.6 & $508(26)$ & $777(83)$ & $667(22)$ & -3.1 & 3.6 \\
\hline OAL0.9 & $487(42)$ & $727(70)$ & $586(17)$ & -3.9 & 4.3 \\
\hline OAL1.2 & $468(33)$ & $742(61)$ & $557(15)$ & -3.6 & 5.2 \\
\hline & & & & & \\
\hline OZOL0.1 & $547(29)$ & $726(65)$ & $581(15)$ & -16.0 & 1.3 \\
\hline OZOL0.3 & $500(33)$ & $595(32)$ & $538(19)$ & -17.3 & 2.4 \\
\hline OZOL0.6 & $487(32)$ & $573(40)$ & $518(15)$ & -20.0 & 3.5 \\
\hline
\end{tabular}




\title{
Antiresorptive and anti-angiogenetic octacalcium phosphate functionalized with bisphosphonates: an in vitro tri-culture study.
}

\author{
Lucia Forte, Paola Torricelli, Elisa Boanini, Massimo Gazzano, Milena Fini, Adriana Bigi
}

\section{Statement of Significance}

Bisphosphonates (BPs) are powerful drugs for the treatment of bone diseases. However, BPs systemic administration suffers several undesirable side effects, which stimulate the development of suitable systems for their local administration. In this study we functionalized octacalcium phosphate (OCP) with alendronate and zoledronate in order to get biomaterials able to couple the good biological performance of OCP with the therapeutic properties of the BPs. The results provide novel information on the interaction between these two potent BPs and octacalcium phosphate. Moreover, the triculture in vitro study indicates that the synthesized composite materials stimulate the production of bone extracellular matrix, inhibit monocytes differentiation into osteoclasts and downregulate the release of Vascular Endothelial Growth Factor (VEGF) in a dose dependent way. The data allow to state that the new composite materials can be usefully employed for the local treatment of diseases involving abnormally high bone resorption. 

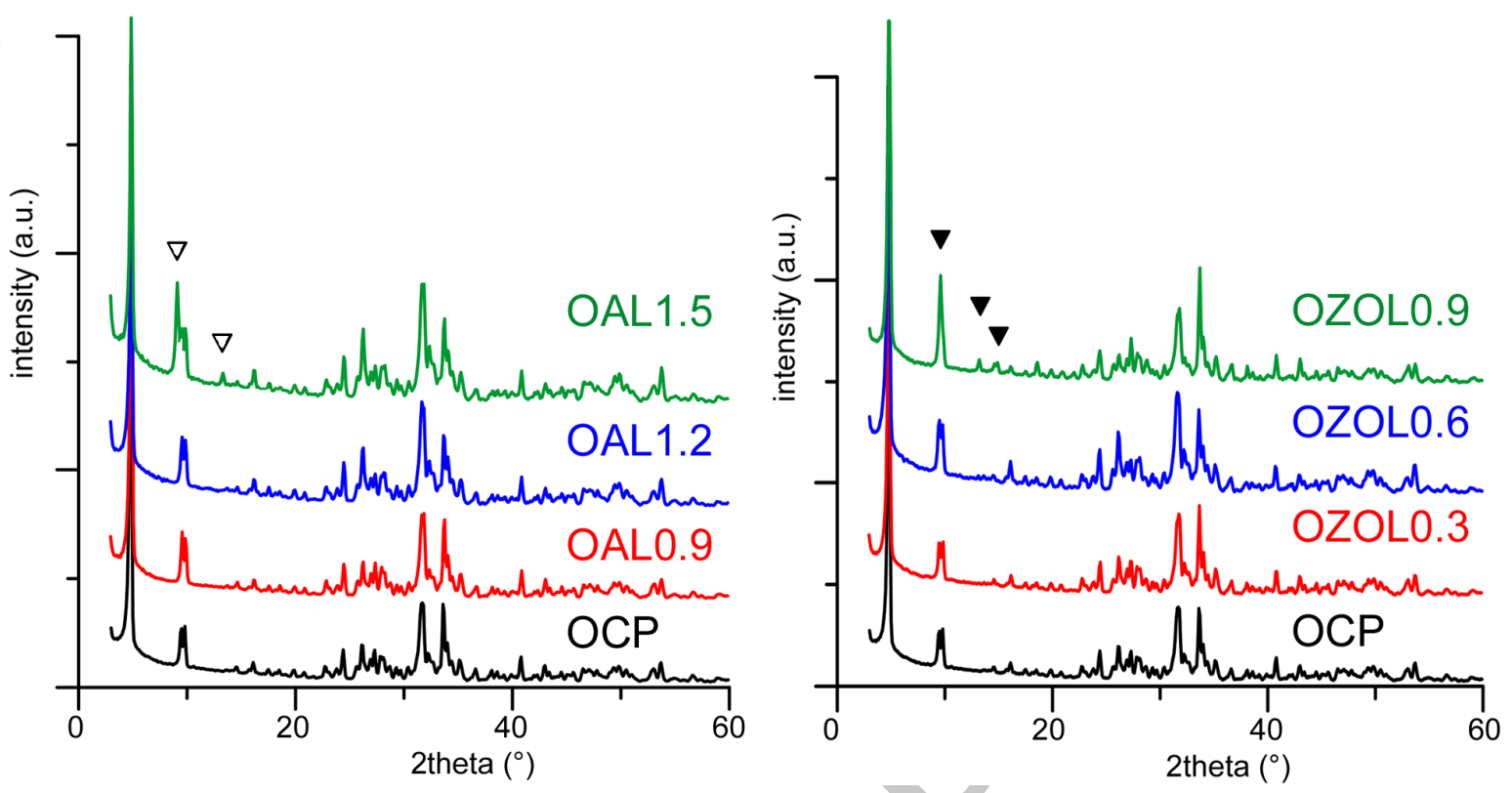

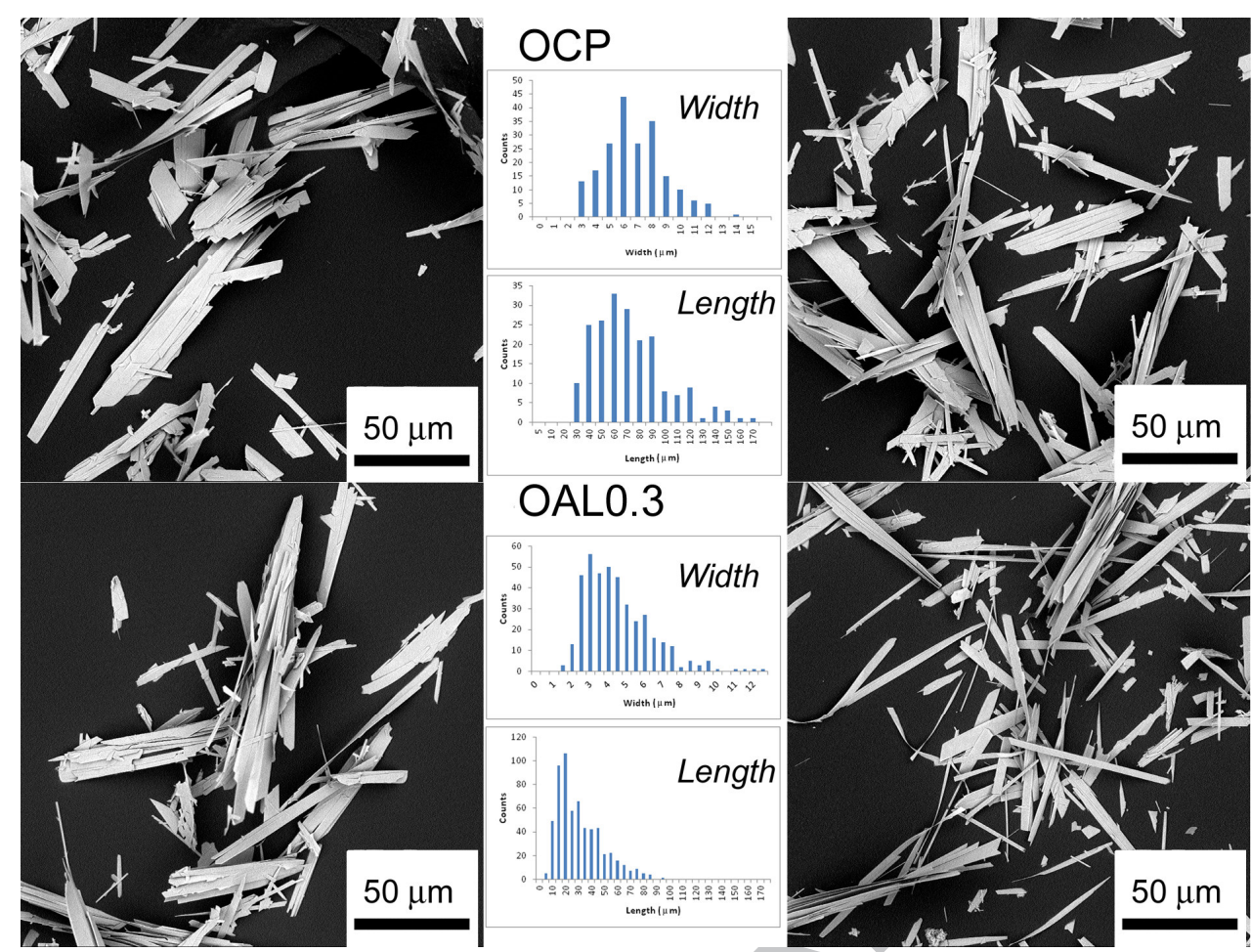

OAL0.9
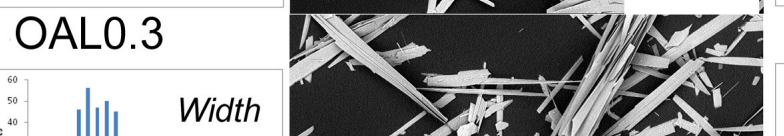

OAL1.2
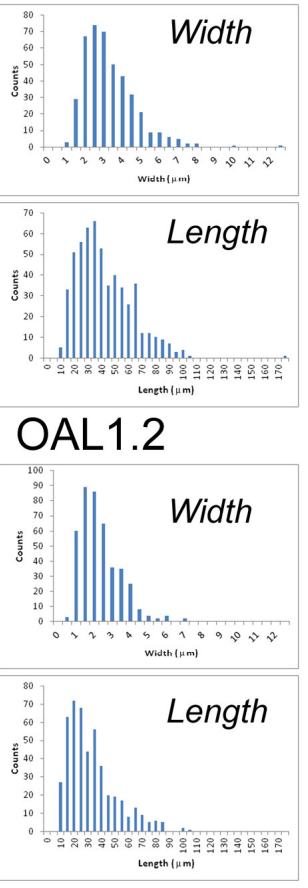


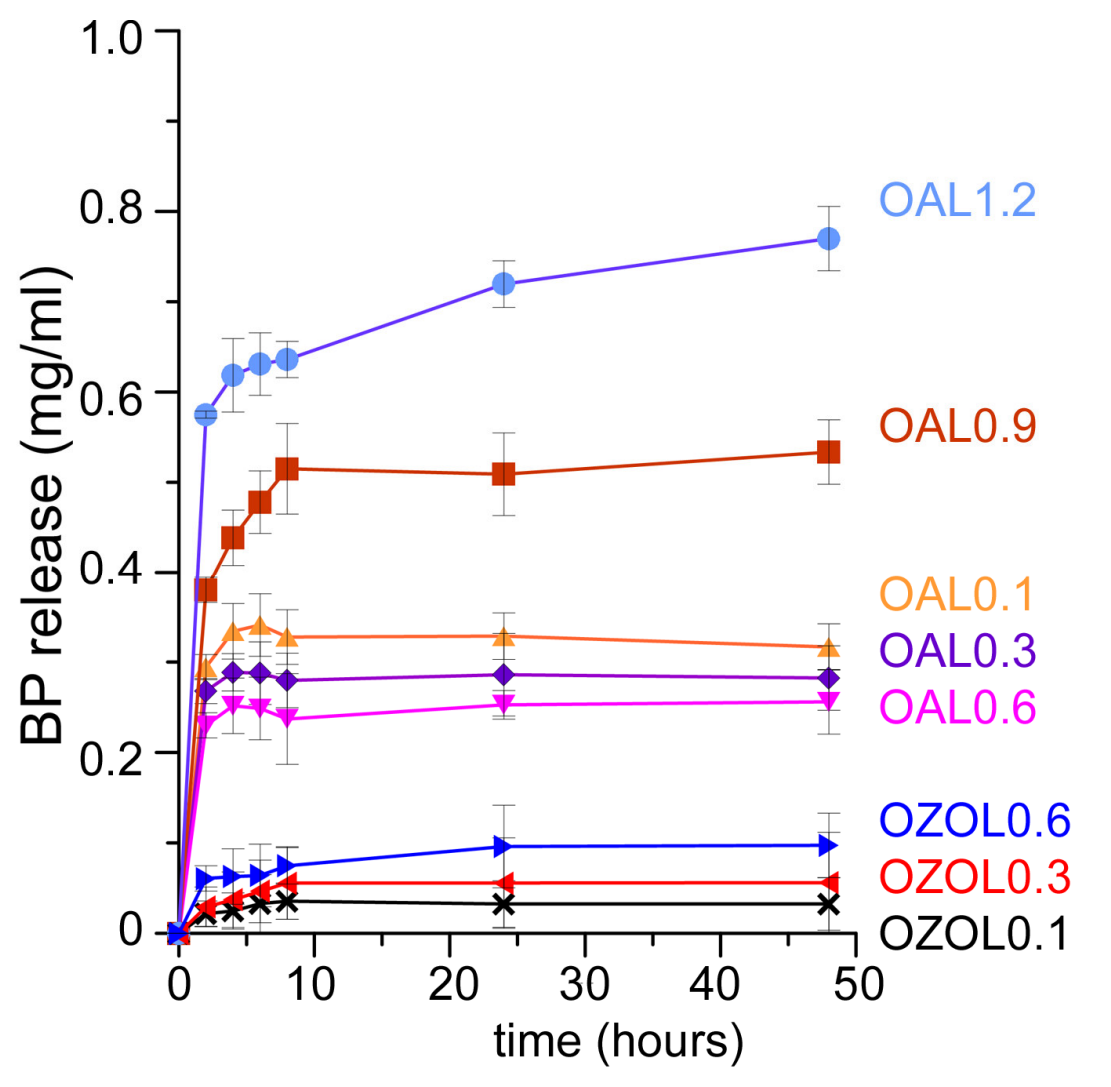



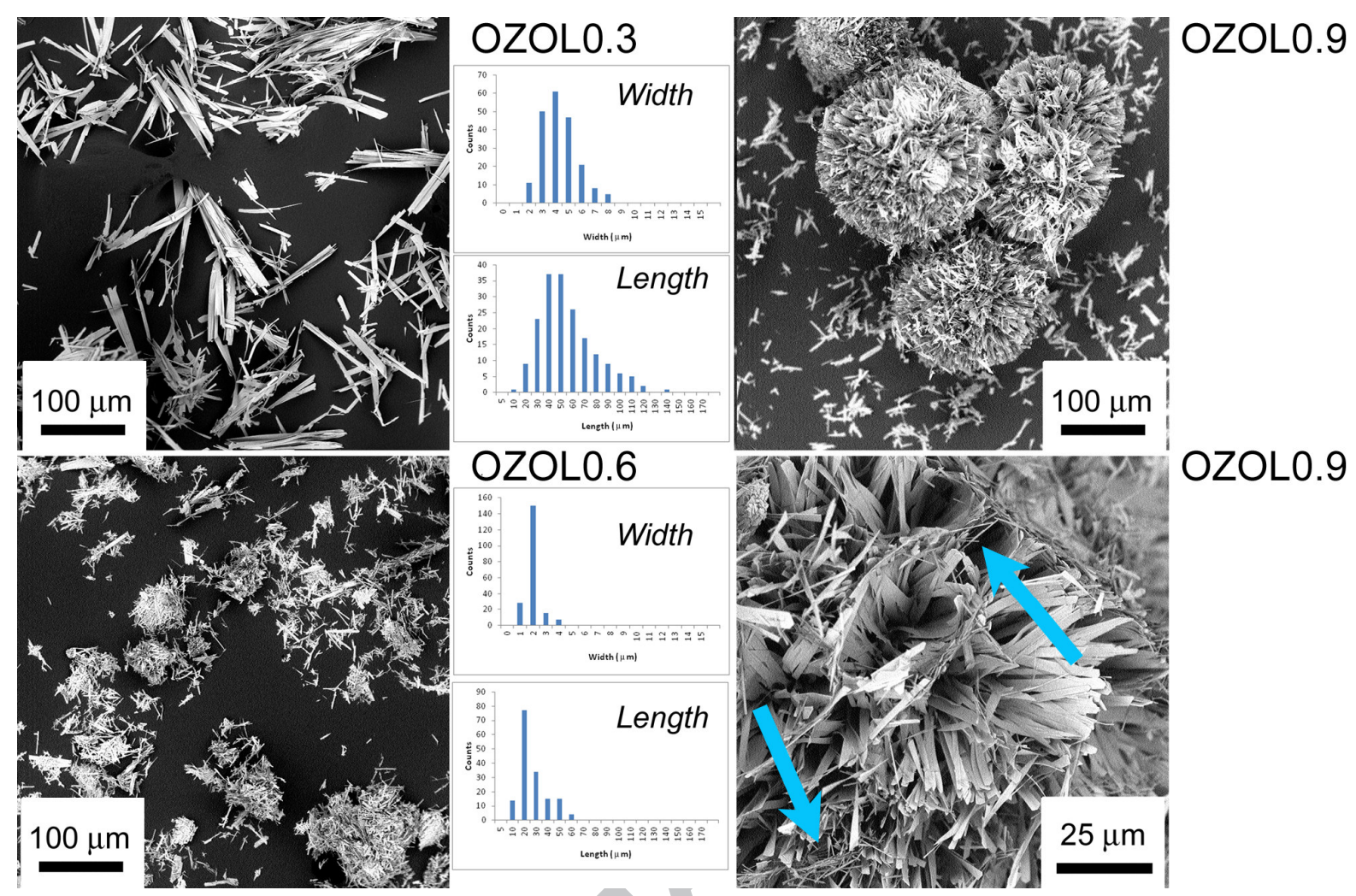

OZOL0.9

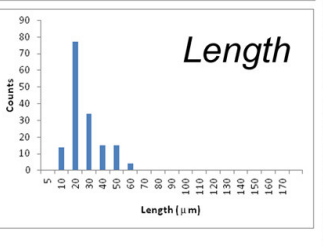

$25 \mu \mathrm{m}$ 


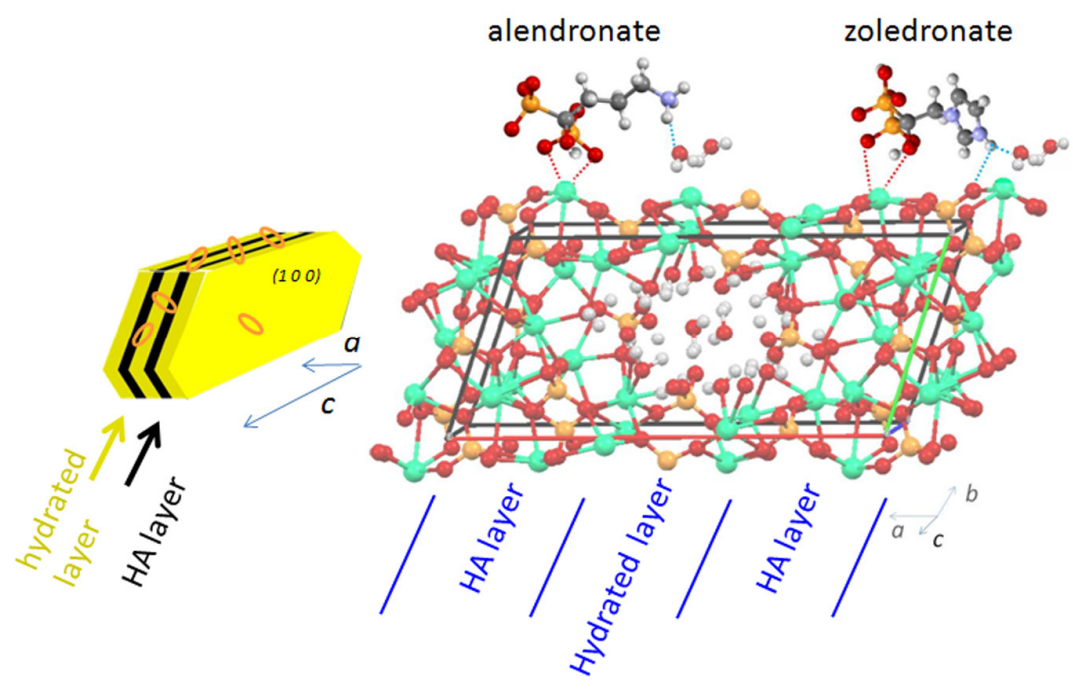




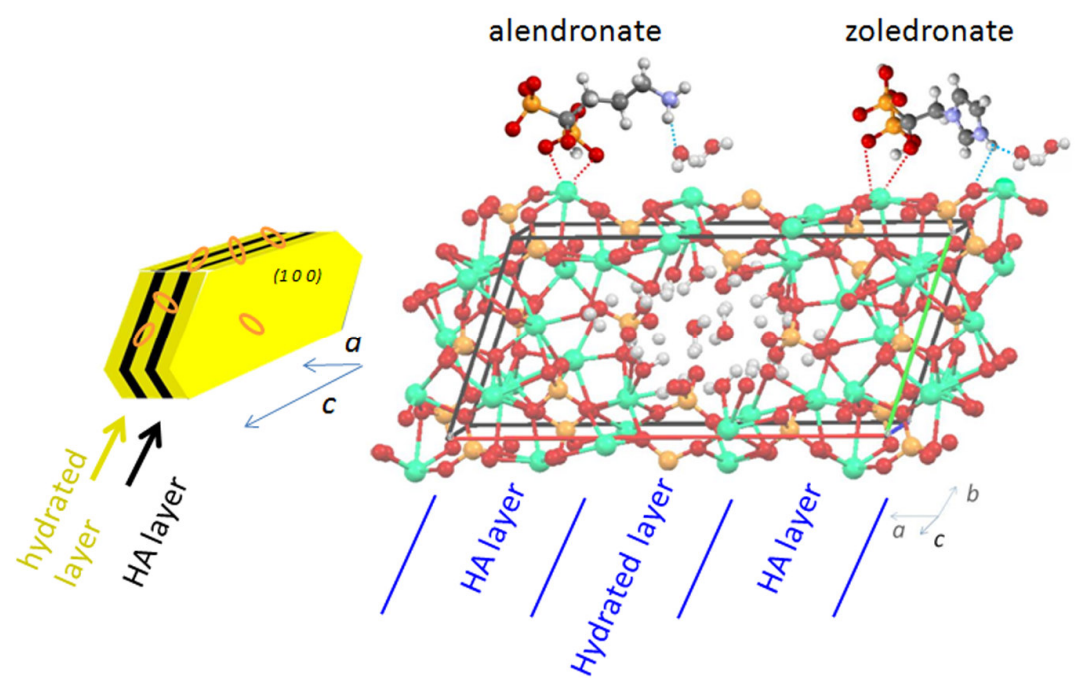




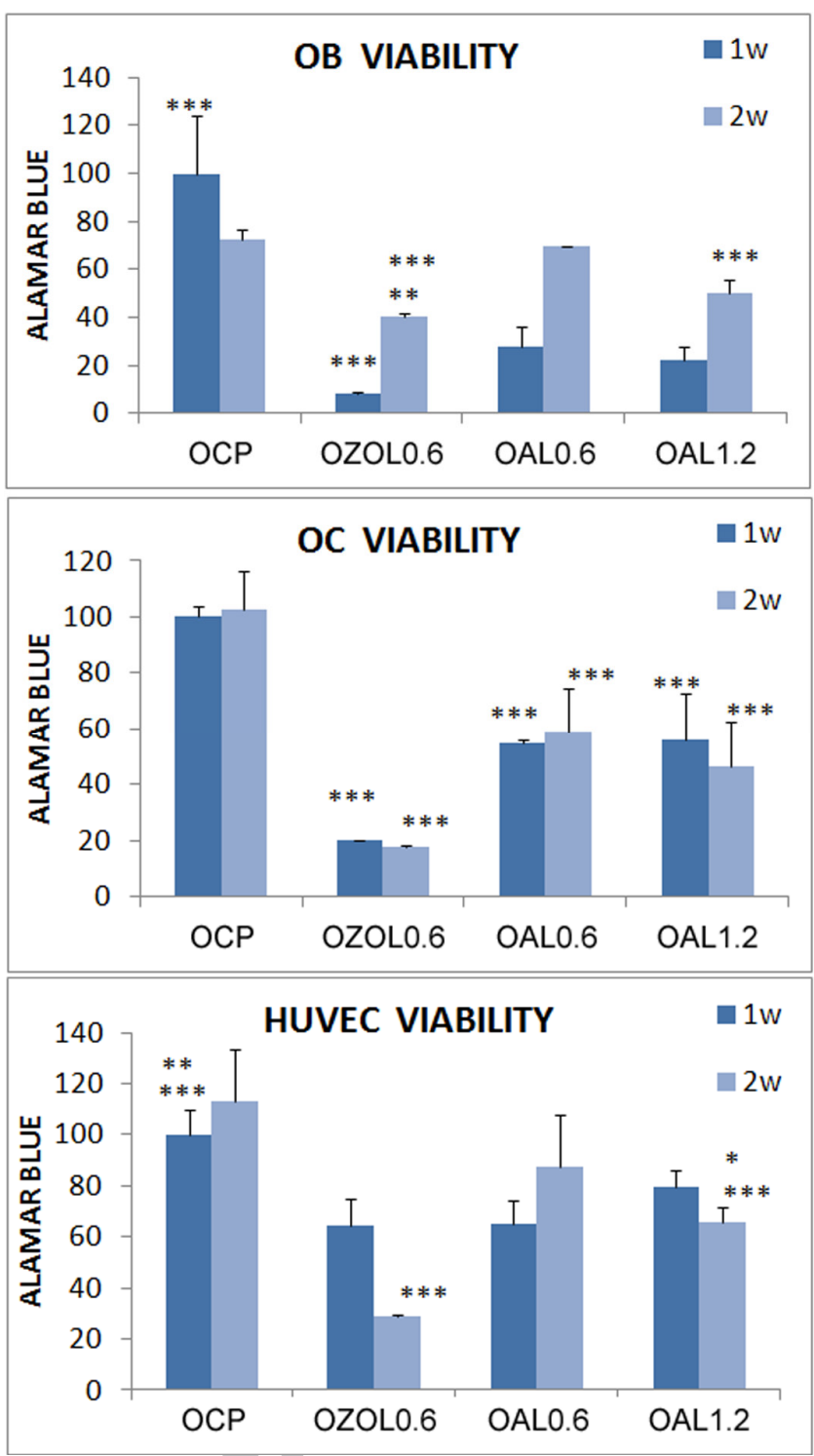




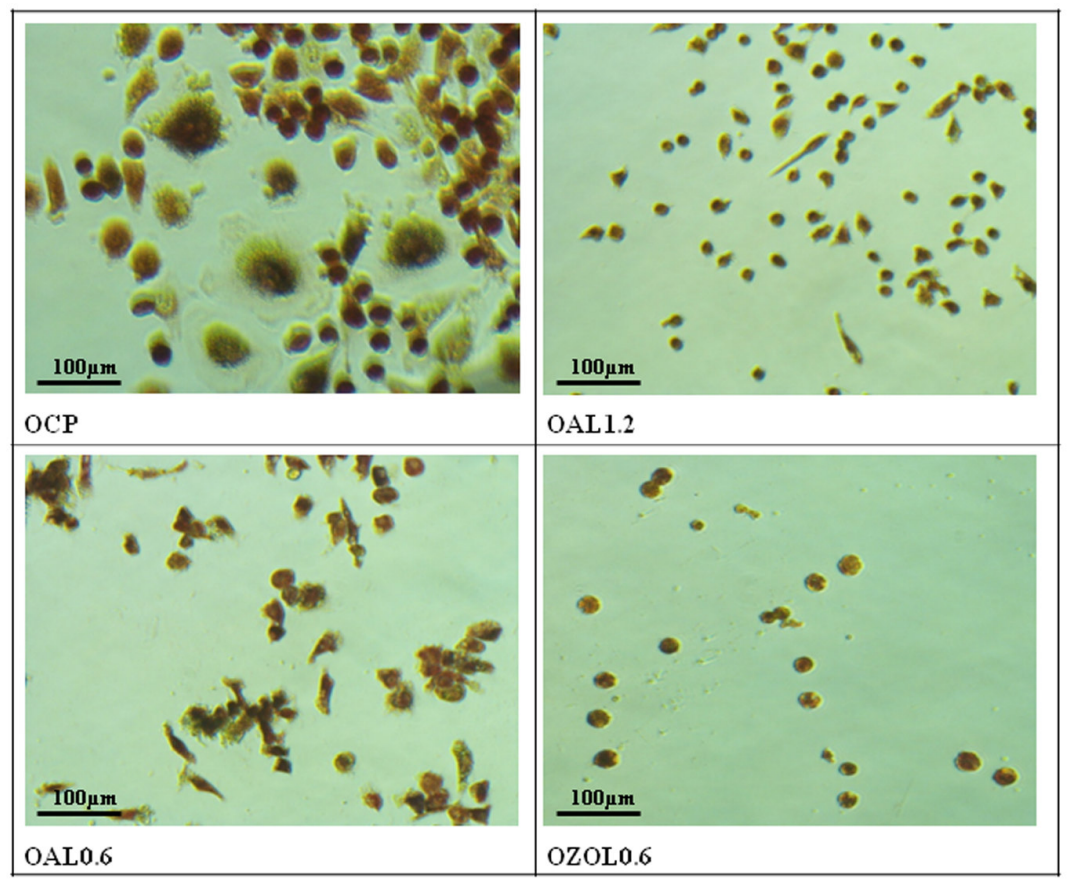




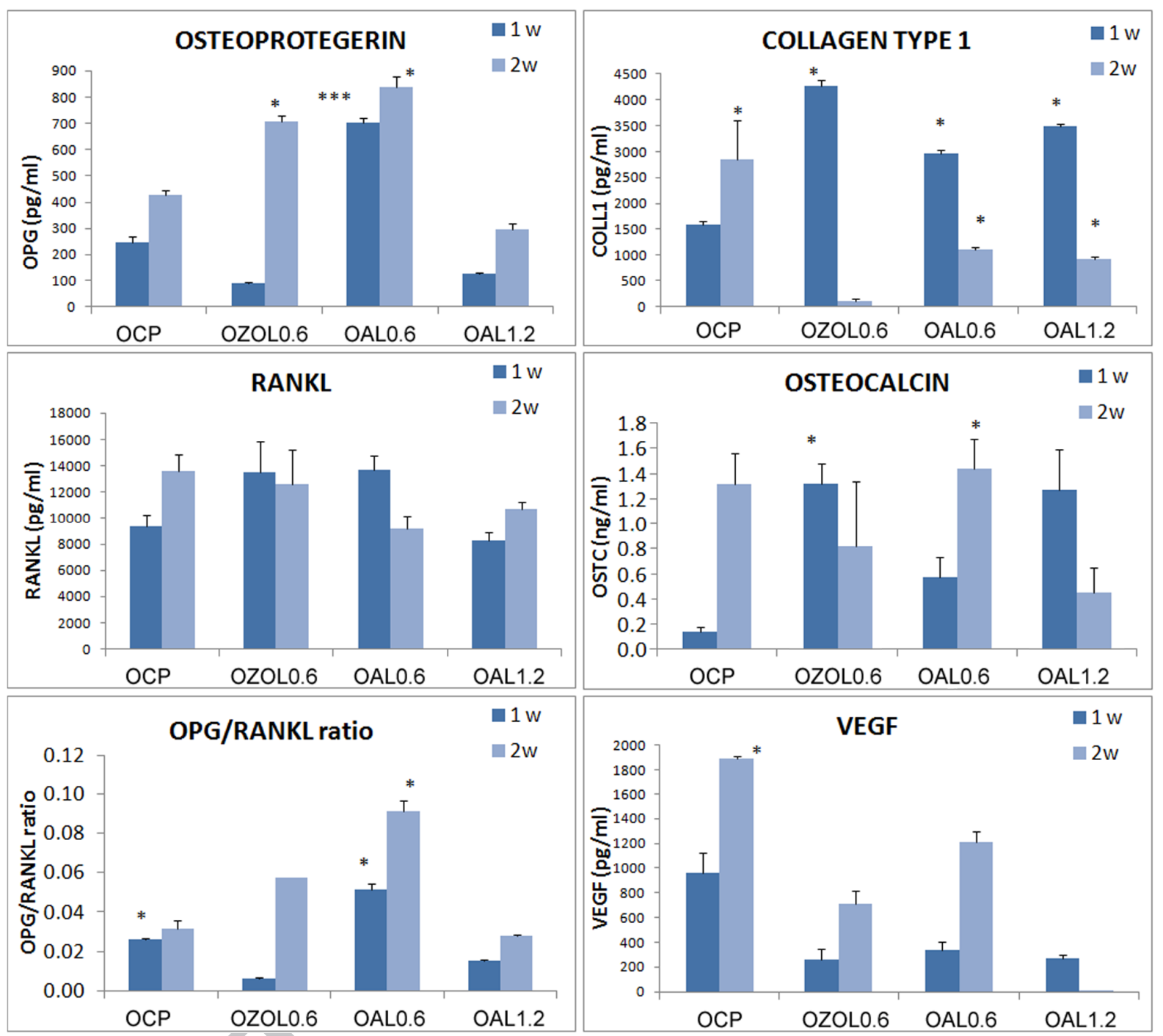




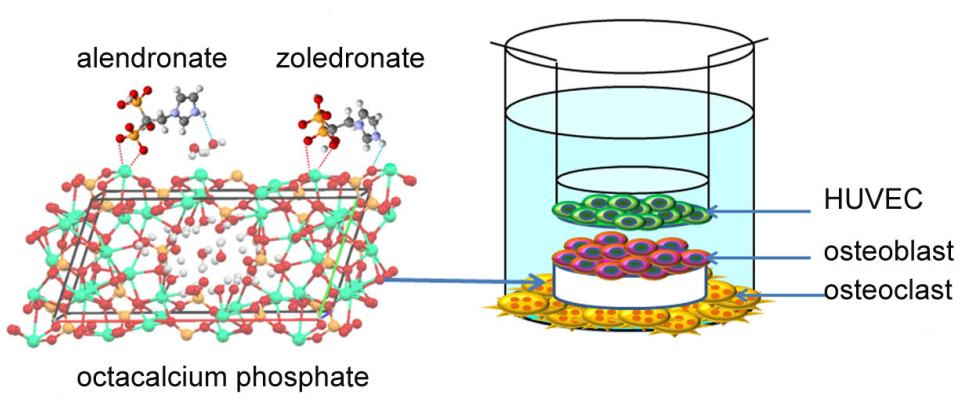

